\title{
dspace.vutbr.cz
}

\section{Minimizing Power Consumption of Automotive AC System by Condenser Fan Speed Control}

\author{
GLOS, J.; KOZOVSKÝ, M.; ŠOLC, F.; VÁCLAVEK, P.
}

Proceedings of the 2020 IEEE 29th International Symposium on Industrial Electronics (ISIE), pp. 148-153

elSBN: 978-1-7281-5635-4

ISSN: 2163-5145

DOl: https://doi.org/10.1109/ISIE45063.2020.9152547

Accepted manuscript

C2020 IEEE. Personal use of this material is permitted. Permission from IEEE must be obtained for all other uses, in any current or future media, including reprinting/republishing this material for advertising or promotional purposes, creating new collective works, for resale or redistribution to servers or lists, or reuse of any copyrighted component of this work in other works. GLOS, J.; KOZOVSKÝ, M.; ŠOLC, F.; VÁCLAVEK, P., " Minimizing Power Consumption of Automotive AC System by Condenser Fan Speed Control ", Proceedings of the 2020 IEEE 29th International Symposium on Industrial Electronics (ISIE), pp. 148-153, 2020.

DOI: 10.1109/ISIE45063.2020.9152547. Final version is available at https://ieeexplore.ieee.org/document/9152547 


\title{
Minimizing Power Consumption of Automotive AC System by Condenser Fan Speed Control
}

\author{
Jan Glos*, Matúš Kozovský $\dagger$, František Šolc ${ }^{\ddagger}$, Pavel Václavek ${ }^{\S}$ \\ CEITEC - Central European Institute of Technology \\ Brno University of Technology \\ Brno, Czech Republic \\ * ORCID ID 0000-0001-9636-1529, ${ }^{\dagger}$ ORCID ID 0000-0002-1547-1003, \\ $\ddagger$ Email: frantisek.solc@ceitec.vutbr.cz, ${ }^{\S}$ ORCID ID 0000-0001-8624-5874
}

\begin{abstract}
This paper introduces three methods of an automotive refrigeration compressor power measurement and computation. All the methods are evaluated on a test bench with convenient results. The model-based method in combination with the condenser model and condenser fan characteristic is then used for assembly of an optimization problem, which has been solved to find an optimal condenser fan speed for a combination of compressor speed and ambient temperature. This method of condensing pressure (temperature) control can be useful to achieve minimal power consumption of the refrigeration system for electric vehicles and even in other application areas with variable speed compressors and condenser fans.

Index Terms-automotive refrigeration, vapor compression refrigeration system, condenser fan speed control, electric compressor control, effectiveness-NTU, power consumption optimization, electric vehicle, heating, ventilation, air conditioning, HVAC, R1234yf
\end{abstract}

\section{INTRODUCTION}

The coming age of electric vehicles (EV) brings requests on energy optimal control of all the devices within the vehicle, as all the devices are powered from high-voltage (HV) battery and they can negatively influence the EV range. The most significant auxiliary from the power consumption perspective is Heating, Ventilation, Air Conditioning, and Refrigeration (HVAC\&R) system. In this paper, we propose a method of minimization of electric compressor power consumption by optimal control of condenser fan, more specifically - the overall power consumption of Air Conditioning (AC) compressor and the condenser fan is minimized.

Vapor compression (refrigeration) system (VCS or VCRS) energy consumption optimization is handled for several industries (building HVAC\&R, supermarket, industrial refrigeration, etc.) and it is solved by different methods. Unfortunately, there are almost no relevant papers on automotive VCRS optimization, as the electric compressors and variable speed condenser fans were introduced quite recently and are usually connected with EVs.

Extremum seeking methods for power consumption minimization [1]-[3] are quite popular due to their independence on the VCRS model. They provide good performance with resistance to disturbances but usually require steady-state conditions, which is not satisfied in automotive applications.
Moreover, a disturbance signal is injected into some actuator and the oscillations might be harmful to some components.

Optimization of VCRS operation by two-state switching of multiple condenser fans was studied in [4]. In [5] the authors assembled the VCRS model and mentioned the reference of condensing temperature (and thus high-side pressure) as an ambient temperature increased by some constant. This approach was tested in simulations [6]. A comparison of different strategies of condenser fans was studied in [7] with fixed head pressure reference and also with floating head pressure setpoint.

Several methods of evaporative condenser fan control were considered in [8] and they derived the formulae for optimal saturated condensation temperature. For air-cooled chillers, the optimal condensing temperature setpoint was discussed in [9] for staged condenser fans.

\section{COMPRESSOR POWER COMPUTATION}

The considered high-voltage electric compressor is shown in Fig. 1 and it is a scroll compressor with the displacement of $33 \mathrm{~cm}^{3}$ intended for $\mathrm{R} 134 \mathrm{a}$ or R1234yf refrigerants. It is equipped by specifically designed power electronics with sensor-less motor control algorithms and LIN communication with the high-level control unit. All the software was created by us, thus it was possible to adjust it to allow compressor power measurements and computations.

The HVAC\&R test bench is also equipped with a variable speed condenser fan, which enables the optimization of condensing pressure (temperature). The circuit is filled with refrigerant R1234yf.

\section{A. Motor control approach}

For electric compressor with 3-phase PMS motor, we can compute the input power as

$$
P=u_{\mathrm{a}} i_{\mathrm{a}}+u_{\mathrm{b}} i_{\mathrm{b}}+u_{\mathrm{a}} i_{\mathrm{b}}
$$

where $i_{x}$ are measured phase currents and $u_{x}$ are phase voltages. Each phase voltage is computed from the PWM duty cycle

$$
u_{x}=D_{x} U_{\mathrm{DC}}
$$




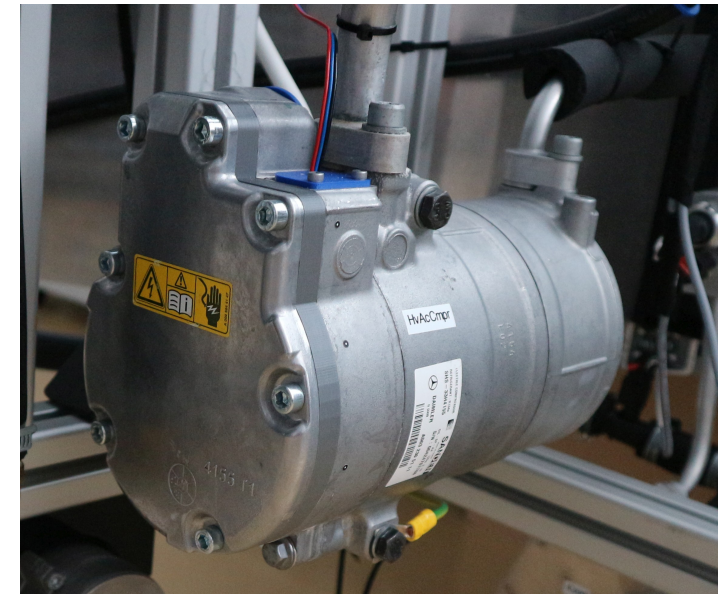

Fig. 1: Automotive refrigerant compressor

where $D_{x} \in\langle 0,1\rangle$ is the duty cycle, $U_{\mathrm{DC}}$ is DC bus voltage and $x \in\{\mathrm{a}, \mathrm{b}, \mathrm{c}\}$ is the phase identifier. Comparing these computations with a real measurement it was found that there is some inaccuracy. Detailed analysis showed, that it is caused by the dead-time of inverter switching elements. Thus a deadtime compensation was introduced and utilized for power consumption computation

$$
u_{x}=\left[D_{x}-c \operatorname{sign}\left(i_{x}\right)\right] U_{\mathrm{DC}},
$$

where $c$ is dead time compensation constant, which is dependent on

- dead time length

- inverter timing characteristics.

The compressor shaft power can be written as

$$
P_{\text {shaft }}=\omega \tau,
$$

where $\omega$ stands for compressor angular velocity with $\tau$ being its torque.

\section{B. Pressure \& Temperature measurement approach}

The compressor in Fig. 1 uses refrigerant for cooling the power electronics, motor winding, and other parts. Therefore, we can suppose that all the energy consumed by the compressor $(P)$ is transferred into the refrigerant in the form of work or heat. The approach will be described in the ph diagram in Fig. 2.

The compressor input power can be computed based on measured variables, particularly inlet and outlet pressures and temperatures. We start from the general equation [10]

$$
P=\dot{m} \Delta h,
$$

where $\dot{m}$ is the refrigerant mass flow rate and $\Delta h$ is specific enthalpy difference between compressor inlet and outlet. The compressor refrigerant mass flow rate can be written as [11]

$$
\dot{m}=\frac{\omega}{2 \pi} \rho_{1} V \eta_{\mathrm{vol}},
$$

where $\rho_{1}$ is the refrigerant volumetric mass density at the compressor inlet, $V$ stands for compressor displacement and

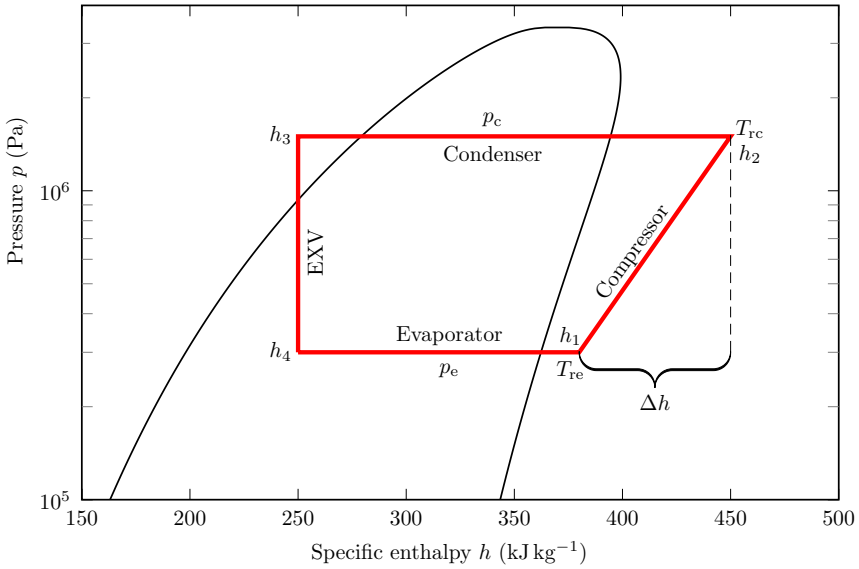

Fig. 2: The ph diagram of the refrigeration cycle

$\eta_{\mathrm{vol}}$ is compressor volumetric efficiency. Specific enthalpy difference can be expressed as

$$
\Delta h=h_{2}-h_{1},
$$

where $h_{1}$ and $h_{2}$ are specific enthalpies at compressor inlet and outlet respectively. As it is not possible to directly measure the specific enthalpy, it is necessary to compute them based on measurable variables

$$
\begin{aligned}
& h_{1}=\mathrm{h}\left(p_{\mathrm{e}}, T_{\mathrm{re}}\right), \\
& h_{2}=\mathrm{h}\left(p_{\mathrm{c}}, T_{\mathrm{rc}}\right),
\end{aligned}
$$

where $p_{e}$ and $p_{c}$ are evaporator and condenser pressures respectively, $T_{\mathrm{re}}$ and $T_{\mathrm{rc}}$ are refrigerant temperatures at evaporator outlet and condenser inlet respectively and $h=\mathrm{h}(p, T)$ is a thermodynamic function returning specific enthalpy based on refrigerant pressure and temperature. The function can be derived from the equation of state and we used a tool CoolProp [12] to obtain particular numeric values. Finally, we get an equation for compressor input power as a combination of equations above

$$
P=\frac{\omega}{2 \pi} \rho_{1} V \eta_{\text {vol }}\left[\mathrm{h}\left(p_{\mathrm{c}}, T_{\mathrm{rc}}\right)-\mathrm{h}\left(p_{\mathrm{e}}, T_{\mathrm{re}}\right)\right] .
$$

\section{Thermodynamic model-based approach}

Compressor power can be also estimated from its model considering overall efficiency

$$
P=\frac{P_{\text {ie }}}{\eta_{\mathrm{o}}},
$$

where $P_{\text {ie }}$ is compressor isentropic power and $\eta_{\mathrm{o}}$ stands for compressor overall efficiency

$$
\eta_{\mathrm{o}}=\eta_{\mathrm{ie}} \eta_{\mathrm{m}} \eta_{\mathrm{mot}},
$$

where $\eta_{\text {ie }}$ is isentropic efficiency, $\eta_{\mathrm{m}}$ mechanical efficiency, and $\eta_{\text {mot }}$ is motor efficiency (considering motor and inverter losses). Then we can write the shaft power as

$$
P_{\text {shaft }}=\frac{P_{\mathrm{ie}}}{\eta_{\mathrm{ie}}}=P \eta_{\mathrm{mot}} \eta_{\mathrm{m}} .
$$


The isentropic compressor power can be written as

$$
P_{\mathrm{ie}}=\dot{m} \Delta h_{\mathrm{ie}}
$$

where $\Delta h_{\mathrm{ie}}$ is isentropic specific enthalpy difference of compressor inlet and outlet

$$
\Delta h_{\mathrm{ie}}=h_{2, \mathrm{ie}}-h_{1},
$$

with $h_{2, \text { ie }}$ being the isentropic specific enthalpy at the compressor outlet. Using thermodynamic functions we can express it as

$$
h_{2, \mathrm{ie}}=\mathrm{h}\left(p_{\mathrm{c}}, \mathrm{s}\left(p_{\mathrm{e}}, T_{\mathrm{re}}\right)\right) \text {, }
$$

where $h=\mathrm{h}(p, s)$ is a thermodynamic function returning specific enthalpy based on pressure and specific entropy and $s=\mathrm{s}(p, T)$ is a function returning specific entropy based on pressure and temperature. Then we can write compressor shaft power as

$$
P_{\text {shaft }}=\frac{\omega}{2 \pi} \rho_{1} V \eta_{\mathrm{vol}} \frac{\mathrm{h}\left(p_{\mathrm{c}}, \mathrm{s}\left(p_{\mathrm{e}}, T_{\mathrm{re}}\right)\right)-\mathrm{h}\left(p_{\mathrm{e}}, T_{\mathrm{re}}\right)}{\eta_{\mathrm{ie}}} .
$$

\section{Combining motor and model-based approach}

If we compare (4) and (17), it is evident that motor power is dependent on motor speed and torque, which can be expressed as

$$
\tau=\frac{\rho_{1} V \eta_{\mathrm{vol}}}{2 \pi \eta_{\mathrm{ie}}}\left[\mathrm{h}\left(p_{\mathrm{c}}, \mathrm{s}\left(p_{\mathrm{e}}, T_{\mathrm{re}}\right)\right)-\mathrm{h}\left(p_{\mathrm{e}}, T_{\mathrm{re}}\right)\right] .
$$

Under the following assumptions

- constant evaporator heat flow rate $\dot{Q}_{\mathrm{e}}$

- constant evaporator pressure $p_{\mathrm{e}}$

- constant compressor suction line superheat

- constant compressor efficiencies $\eta_{\mathrm{vol}}, \eta_{\mathrm{ie}}, \eta_{\mathrm{m}}$ and $\eta_{\mathrm{mot}}$

we can quite easily analyze, which variables the torque is dependent on. The fraction in (18) is constant (even compressor inlet density due to constant evaporator pressure and superheat), the term $\mathrm{h}\left(p_{\mathrm{e}}, T_{\mathrm{re}}\right)$ is also constant and the only variable term is $\mathrm{h}\left(p_{\mathrm{c}}, \mathrm{s}\left(p_{\mathrm{e}}, T_{\mathrm{re}}\right)\right)$. Under assumptions above the specific entropy is also constant, and we get an important finding, that torque is a function of condenser pressure

$$
\tau=f\left(p_{\mathrm{c}}\right)
$$

shown in Fig. 3, and subsequently

$$
P_{\text {shaft }}=\omega f\left(p_{\mathrm{c}}\right)=\mathrm{g}\left(\omega, p_{\mathrm{c}}\right) .
$$

\section{CONDENSER THERMAL FLOWS MODEL}

Heat flow rate caused by transportation of the air into and out of the condenser can be described by simplified steadyflow thermal energy equation [13]

$$
\dot{Q}=\dot{m}_{\mathrm{a}} c_{\mathrm{a}}\left(T_{\mathrm{ai}}-T_{\mathrm{ao}}\right),
$$

where $\dot{m}_{\mathrm{a}}$ is air mass flow rate influenced by condenser fan, $c_{\mathrm{a}}$ is the air specific heat capacity and $T_{\mathrm{ai}}$ and $T_{\mathrm{ao}}$ are the inlet and outlet temperatures of the air respectively.

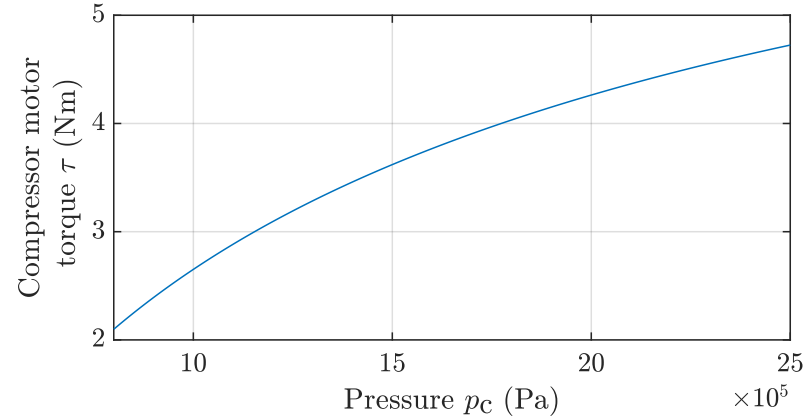

Fig. 3: Compressor torque dependency on condenser pressure

The heat flow rate between the refrigerant and air can be expressed using Logarithmic Mean Temperature Difference (LMTD) [13]

$$
\dot{Q}=U A \Delta T_{\mathrm{HX}}
$$

where $U$ is overall heat transfer coefficient, $A$ is the heat exchanger effective area and $\Delta T_{\mathrm{HX}}$ is logarithmic temperature difference

$$
\Delta T_{\mathrm{HX}}=\frac{\Delta T_{\mathrm{A}}-\Delta T_{\mathrm{B}}}{\ln \frac{\Delta T_{\mathrm{A}}}{\Delta T_{\mathrm{B}}}}=\frac{\left(T_{\mathrm{ri}}-T_{\mathrm{ao}}\right)-\left(T_{\mathrm{ro}}-T_{\mathrm{ai}}\right)}{\ln \frac{\left(T_{\mathrm{ri}}-T_{\mathrm{ao}}\right)}{\left(T_{\mathrm{ro}}-T_{\mathrm{ai}}\right)}},
$$

which can be for a constant temperature of one medium $\left(T_{\text {ro }}=\right.$ $\left.T_{\mathrm{ri}}=T_{\mathrm{r}}\right)$ simplified to

$$
\Delta T_{\mathrm{HX}}=\frac{T_{\mathrm{ai}}-T_{\mathrm{ao}}}{\ln \frac{\left(T_{\mathrm{r}}-T_{\mathrm{ao}}\right)}{\left(T_{\mathrm{r}}-T_{\mathrm{ai}}\right)}} .
$$

The second possibility of heat flow rate computation is Effectiveness - Number of Transfer Units ( $\epsilon$-NTU) method [13] based on the determination of maximal HX heat flow rate and then computation of $\mathrm{HX}$ effectiveness. We can write the dimensionless $N T U$ coefficient as

$$
N T U \equiv \frac{U A}{C_{\min }},
$$

where $C_{\min }$ is defined as

$$
C_{\min } \equiv \min \left(C_{\mathrm{c}}, C_{\mathrm{h}}\right),
$$

where $C_{\mathrm{c}}$ and $C_{\mathrm{h}}$ stand for heat capacity rates of cold and hot stream respectively and are described by

$$
C=\dot{m} c_{p}
$$

Then we express heat capacity ratio

$$
C_{\mathrm{r}} \equiv \frac{C_{\min }}{C_{\max }},
$$

and as the $c_{p}$ of two-phase refrigerant in the condenser is infinite [14], the heat capacity ratio becomes $C_{\mathrm{r}}=0$. Then we can use the equation

$$
\epsilon=1-\exp (-N T U),
$$




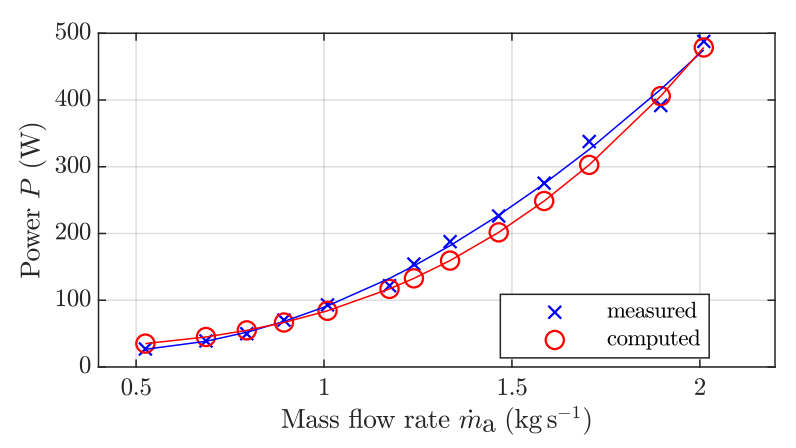

Fig. 4: Condenser fan power dependency

which holds for any heat exchanger without restrictions on flow arrangement. Then the heat flow rate of HX can be computed by

$$
\dot{Q}=\epsilon C_{\text {min }}\left(T_{\text {ri }}-T_{\text {ai }}\right)=\epsilon C_{\text {min }}\left(T_{\mathrm{r}}-T_{\text {ai }}\right) .
$$

Both the $\epsilon$ and $C_{\min }$ are dependent only on the air mass flow rate $\dot{m}_{\mathrm{a}}$.

The power consumption of the condenser fan was measured on the test bench with the results shown in Fig. 4, which conform the expected fan characteristics

$$
P_{\text {fan }}=27+55.59 \dot{m}_{\mathrm{a}}^{3} .
$$

\section{POWER CONSUMPTION MINIMIZATION}

We define the overall power consumption of the system as

$$
P_{\text {oa }} \equiv P_{\text {cmpr }}+P_{\text {fan }},
$$

and we need to minimize it to achieve energy optimal operation of the VCRS system. The goal of this section is to express the overall power consumption as a function of condenser pressure $p_{\mathrm{c}}$ and then to find an optimal condenser pressure $p_{\mathrm{c}}^{*}$, for which the overall power consumption will be minimal (under defined conditions).

Compressor power can be from (13), (20) and with substituting $P_{\text {cmpr }}=P$ easily described by

$$
P_{\text {cmpr }}=\frac{P_{\text {shaft }}}{\eta_{\text {mot }} \eta_{\mathrm{m}}}=\frac{\omega \tau}{\eta_{\text {mot }} \eta_{\mathrm{m}}}=\frac{\omega \mathrm{f}\left(p_{\mathrm{c}}\right)}{\eta_{\mathrm{mot}} \eta_{\mathrm{m}}}
$$

and for fan power, we can write

$$
P_{\text {fan }}=27+55.59 \dot{m}_{\mathrm{a}}^{3},
$$

but $\dot{m}_{\mathrm{a}}$ is not known. Then it is necessary to express $\dot{m}_{\mathrm{a}}$ from (30) as a function of condenser pressure $p_{c}$ to enable energy optimization. After inserting into the original equation we get

$$
\dot{Q}=\left[1-\exp \left(-\frac{U A}{\dot{m}_{\mathrm{a}} c_{p}}\right)\right] \dot{m}_{\mathrm{a}} \mathrm{c}_{\mathrm{a}}\left(T_{\mathrm{r}}-T_{\mathrm{ai}}\right),
$$

from where it is unfortunately not possible to express $\dot{m}_{\mathrm{a}}$ directly. Therefore, an $\epsilon$-NTU approximation was introduced and it summarizes the terms

$$
\nu\left(\dot{m}_{\mathrm{a}}\right)=\left[1-\exp \left(-\frac{\mathrm{UA}}{\dot{m}_{\mathrm{a}} c_{p}}\right)\right] \dot{m}_{\mathrm{a}} c_{\mathrm{a}}
$$

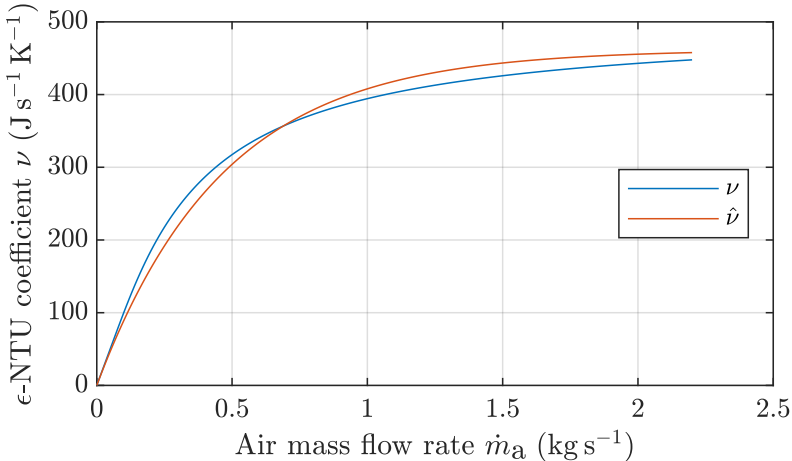

Fig. 5: $\epsilon$-NTU approximation

shaped as

$$
\hat{\nu}\left(\dot{m}_{\mathrm{a}}\right)=a\left[1-\exp \left(-b \dot{m}_{\mathrm{a}}\right)\right],
$$

with quite good compliance shown in Fig. 5. The approximation coefficients $a, b$ are dependent on heat exchanger properties (constants $A, U$ ) and mass flow rate range. Using the approximation above

$$
\begin{aligned}
\dot{Q} & =\hat{\nu}\left(\dot{m}_{\mathrm{a}}\right)\left(T_{\mathrm{r}}-T_{\mathrm{ai}}\right) \\
& =a\left[1-\exp \left(-b \dot{m}_{\mathrm{a}}\right)\right]\left(T_{\mathrm{r}}-T_{\mathrm{ai}}\right)
\end{aligned}
$$

the $\dot{m}_{\mathrm{a}}$ can be expressed as

$$
\dot{m}_{\mathrm{a}}=\frac{\ln \left(1-\frac{\dot{Q}}{a\left(T_{\mathrm{r}}-T_{\mathrm{in}}\right)}\right)}{-b} .
$$

The last step is evaluating the term $T_{\mathrm{r}}$ in the equation above. As it is considered to be a condensing temperature, which is dependent only on refrigerant pressure in the two-phase region, we can write

$$
T_{\mathrm{r}}=\mathrm{T}_{\mathrm{sat}}\left(p_{\mathrm{c}}\right),
$$

where $\mathrm{T}_{\text {sat }}(p)$ is a thermodynamic function returning saturated temperature for defined pressure. This dependency is known for each refrigerant (can be obtained from e.g. [12]), and we can easily find $2^{\text {nd }}$ order polynomial approximation of this function

$$
T_{\mathrm{r}}=\hat{\mathrm{T}}_{\mathrm{sat}}\left(p_{\mathrm{c}}\right)=z_{1} p_{\mathrm{c}}^{2}+z_{2} p_{\mathrm{c}}+z_{3},
$$

which is valid for reasonable pressure and temperature range with coefficients $z_{1}=-6.83 \times 10^{-12}, z_{2}=5.05 \times 10^{-5}$, and $z_{3}=268.65$.

Then we substitute (41) into (39), then resulting $\dot{m}_{\mathrm{a}}$ into (34) and finally this fan power into overall power equation (32). The arising function

$$
P_{\mathrm{oa}}=l\left(p_{\mathrm{c}}, T_{\mathrm{in}}, \omega\right)
$$




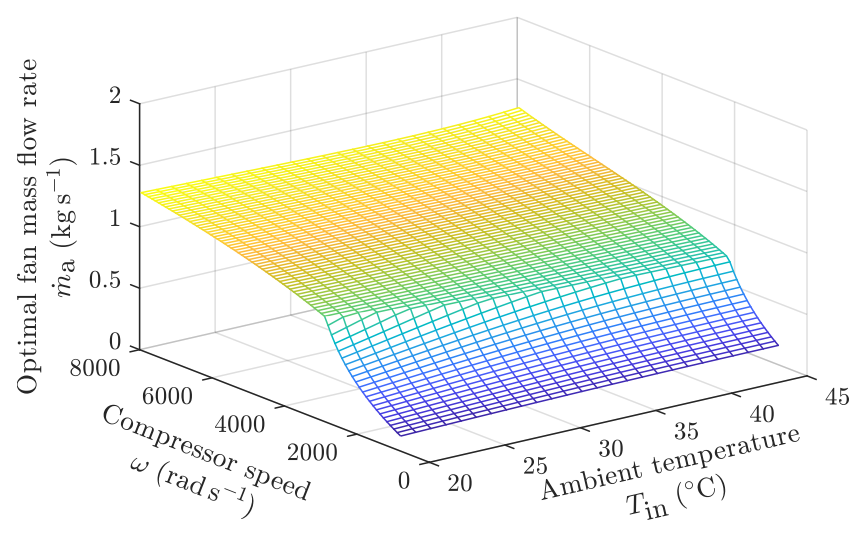

Fig. 6: Optimal condenser air mass flow rate

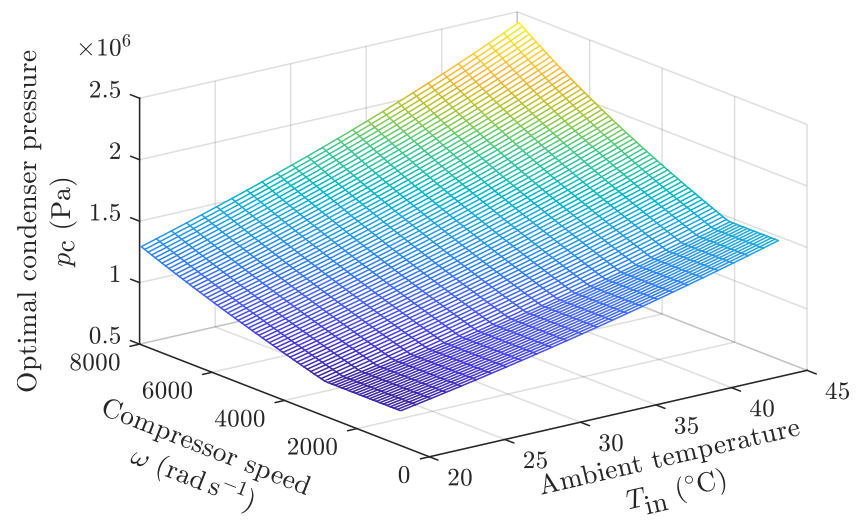

Fig. 7: Optimal condenser refrigerant pressure

needs to be minimized for each combination of ambient temperature $T_{\text {in }}$ and compressor speed $\omega$

$$
\begin{aligned}
& \min \quad P_{\text {oa }}\left(p_{\mathrm{c}}\right), \\
& \text { subject to } \\
& p_{\mathrm{c}} \in\left\langle p_{\min }, p_{\max }\right\rangle \\
& T_{\text {in }}, \omega \text { given. }
\end{aligned}
$$

We used MATLAB function fminbnd for the minimization of overall power. The function employs golden-section search and parabolic interpolation for finding a minimum of singlevariable function on a fixed interval. Due to high problem complexity and non-linearity, it was necessary to properly adjust the pressure range $\left\langle p_{\min }, p_{\max }\right\rangle$. The $p_{\max }$ was kept constant for all iterations of the algorithm $\mathrm{p}_{\max }=2.5 \mathrm{MPa}$. Assuming that condenser pressure is always equal or higher with rising ambient temperature $T_{\text {in }}$ and/or compressor speed $\omega$, the minimal pressure is adjusted in each optimization step based on the previous value.

The CoolProp library [12] was used in thermodynamic computations to obtain the refrigerant state variables and properties.

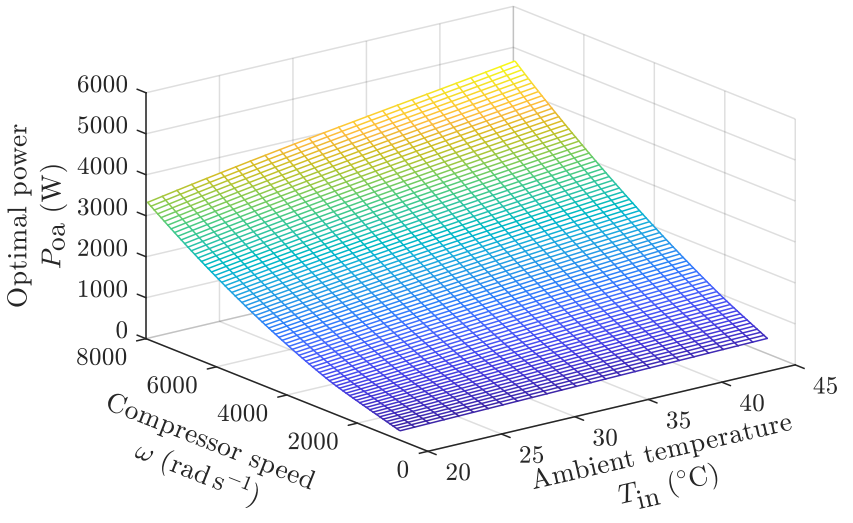

Fig. 8: Expected optimal overall system power

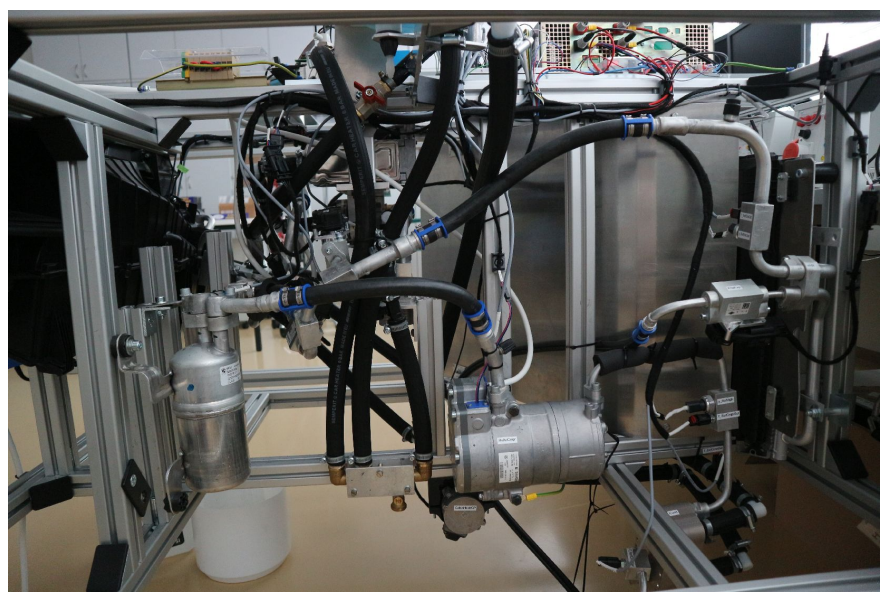

Fig. 9: Automotive HVAC\&R test bench

\section{EXPERIMENTAL VERIFICATION}

The methods of compressor power measurement and computation were verified in real operation on the automotive HVAC test bench (Fig. 9). The measurement results completed with computed values are shown in Fig. 10. The first plot shows the pressures in the system together with the low-pressure reference value. The second plot contains the measured temperature of the air at the evaporator outlet and the third plot shows compressor speed. The last plot includes compressor input power obtained by three methods: modelbased, using pressure \& temperature measurements, and by motor control measurements.

The model-based method is based on (13) and (17) with the constants defined in Table I. It gives results with very good correspondence to the motor control measurements. The pressure \& temperature method use (10) and it gives divergent values compared to measurements. There are two main reasons for that - firstly, the method is dependent on temperature sensors, which are mounted in (or on) aluminum pipes. Thus, there is some time, which is needed for the pipes and sensors to be heated up or cooled down (approx. $50 \mathrm{~s}$ from compressor start). Secondly, the temperature sensor of the compressor 

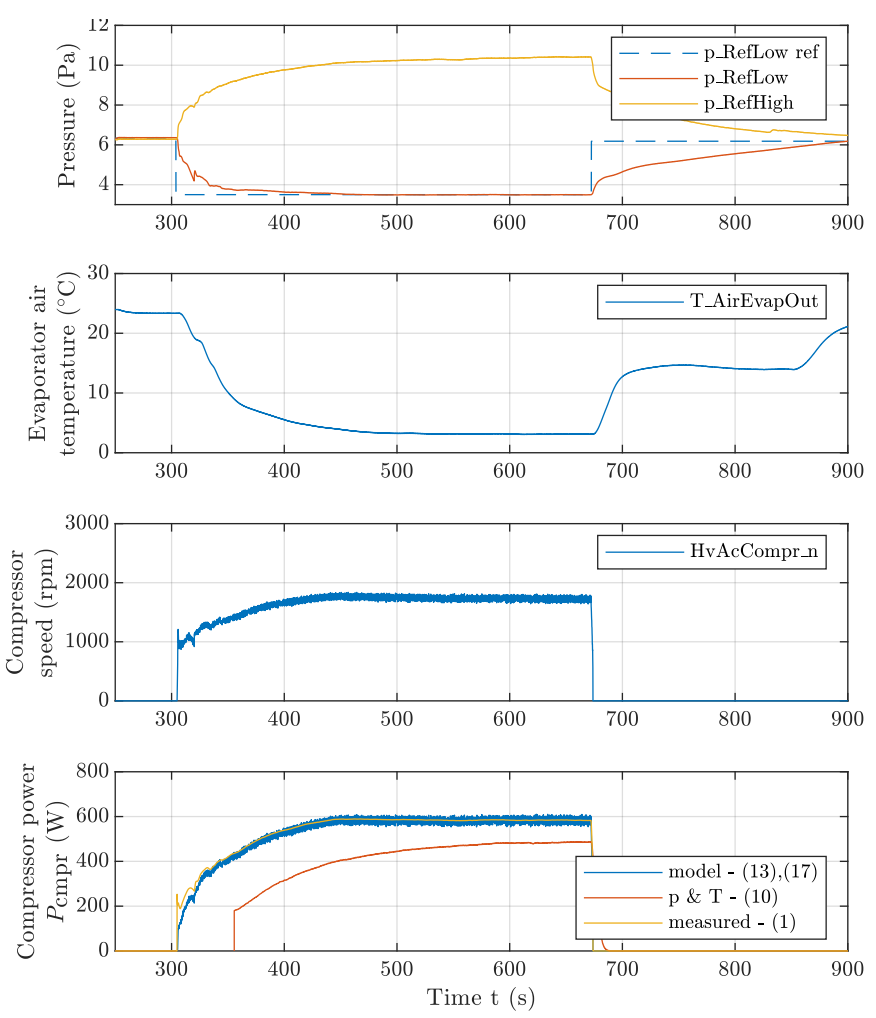

Fig. 10: Comparison of compressor power measurement and computation in real operation

TABLE I: Compressor power computation constants

\begin{tabular}{lll}
\hline Constant & Symbol & Value \\
\hline Displacement & $V$ & $33 \mathrm{~cm}^{3}$ \\
Volumetric efficiency & $\eta_{\text {vol }}$ & 0.9 \\
Isentropic efficiency & $\eta_{\text {ie }}$ & 0.65 \\
Mechanical efficiency & $\eta_{\mathrm{m}}$ & 0.9 \\
Motor efficiency & $\eta_{\mathrm{mot}}$ & 0.95 \\
\hline
\end{tabular}

outlet is not exactly at the outlet, but in the pipe approx. $20 \mathrm{~cm}$ from the compressor port. As the refrigerant temperature is substantially higher compared to ambient temperature, there are some thermal losses to ambient and the temperature reading is lower. This inaccuracy could be compensated, but the model-based approach will always be more accurate and thus it was a preferable choice (also in optimization task).

\section{CONCLUSION}

In this paper, we derived and presented three methods of refrigerant compressor power measurement and computation. The methods were tested in real operation and give satisfactory results. The model-based method is then used in overall compressor and fan power minimization, which was introduced as a map of fan speed for defined compressor speed and ambient temperature.

We made some neglections during the method derivation, so the future improvements could focus on their minimization, especially the condenser model could be divided into multiple sections and some constants (like efficiencies) might become functions of compressor speed, pressure ratio, etc.

Also, detailed verification in a climatic chamber under whole operating conditions would be valuable for future development.

This method could also be the baseline for future improvements, which could include real-time power consumption optimization with the self-learning features.

\section{ACKNOWLEDGMENT}

This research was carried out under the project NCK KUI TA ČR TN01000024.

This research was carried out under the project LQ1601 CEITEC 2020.

The research was supported by the research infrastructure of CEITEC - Central European Institute of Technology.

\section{REFERENCES}

[1] D. Burns, C. Laughman, and D. J. Burns, "Extremum Seeking Control for Energy Optimization of Vapor Compression Systems Extremum Seeking Control for Energy Optimization of Vapor Compression Systems," in International Refrigeration and Air Conditioning Conference, 2012.

[2] D. J. Burns, C. R. Laughman, and M. Guay, "Proportional-integral extremum seeking for vapor compression systems," in Proceedings of the American Control Conference, vol. 2016-July, pp. 2352-2357, Institute of Electrical and Electronics Engineers Inc., July 2016.

[3] L. Dong, Y. Li, T. I. Salsbury, and J. M. House, "Self-optimizing control and mode switching for multi-functional Variable Refrigerant Flow air conditioning systems via extremum seeking," in Proceedings of the American Control Conference, vol. 2016-July, pp. 593-598, Institute of Electrical and Electronics Engineers Inc., July 2016.

[4] F. W. Yu and K. T. Chan, "Modelling of a condenser-fan control for an air-cooled centrifugal chiller," Applied Energy, vol. 84, no. 11, pp. 11171135, 2007.

[5] T. G. Hovgaard, L. F. Larsen, M. J. Skovrup, and J. B. Jørgensen, "Power consumption in refrigeration systems - Modeling for optimization," in 2011 International Symposium on Advanced Control of Industrial Processes, ADCONIP 2011, pp. 234-239, 2011.

[6] J. Glos, P. Václavek, and P. Blaha, "Energy efficient control of a heat pump in fully electric vehicle," in Proceedings of the 7th European Transport Research Arena 2018, pp. 1-10, Apr. 2018.

[7] K. A. Manske, D. T. Reindl, and S. A. Klein, "Evaporative condenser control in industrial refrigeration systems," International Journal of Refrigeration, vol. 24, pp. 676-691, July 2001.

[8] R. J. Love, D. J. Cleland, T. B. Jekel, and D. T. Reindl, "Improved control of condensers," in ASHRAE Transactions, vol. 125, pp. 554$562,2019$.

[9] K. T. Chan and F. W. Yu, "Optimum setpoint of condensing temperature for air-cooled chillers," HVAC and R Research, vol. 10, no. 2, pp. 113$127,2004$.

[10] Y. A. Cengel and M. A. Boles, Thermodynamics: an Engineering Approach. McGraw-Hill Education, 2015.

[11] Q. Zhang and M. Canova, "Modeling and output feedback control of automotive air conditioning system," International Journal of Refrigeration, vol. 58, pp. 207-218, Oct. 2015.

[12] I. H. Bell, J. Wronski, S. Quoilin, and V. Lemort, "Pure and Pseudopure Fluid Thermophysical Property Evaluation and the Open-Source Thermophysical Property Library CoolProp," Industrial \& Engineering Chemistry Research, vol. 53, no. 6, pp. 2498-2508, 2014.

[13] L. A. Incropera Frank P., Dewitt D.P., Bergman T. L., Fundamentals of Heat and Mass Transfer. John Wiley \& Sons, 2011.

[14] M. W. Browne and P. K. Bansal, "An elemental NTU- $\epsilon$ model for vapour-compression liquid chillers," International Journal of Refrigeration, vol. 24, pp. 612-627, July 2001. 